\title{
Spinal cord swelling in patients with cervical compression myelopathy
}

\author{
Naohiro Tachibana', Takeshi Oichi', So Kato', Yusuke Sato ${ }^{1}$, Hiroyuki Hasebe', Shima Hirai ${ }^{1}$, Yuki Taniguchi $^{1}$, \\ Yoshitaka Matsubayashi ${ }^{1}$, Harushi Mori ${ }^{2}$, Sakae Tanaka ${ }^{1}$ and Yasushi Oshima ${ }^{1 *}$
}

\begin{abstract}
Background: Intramedullary hyperintense lesions associated with spinal cord edema on T2-weighted MR images $(\mathrm{T} 2 \mathrm{WI})$ are rare findings in patients with cervical spondylosis and are poorly characterized. We investigated the clinical characteristics of spinal cord edema due to cervical spondylosis (SCECS).

Methods: In total, 214 patients with cervical spondylotic myelopathy who underwent surgery between April 2007 and March 2017 were divided into SCECS and non-SCECS groups with SCECS defined as follows: (1) intramedullary signal intensity (ISI) of the cervical spinal cord in sagittal T2WI extending to more than one vertebral body height; (2) "fuzzy" ISI, recognized as a faint intramedullary change with a largely indistinct and hazy border; and (3) a larger sagittal diameter of the spinal cord segment with ISI just above or below the cord compression area compared with areas of the cervical spine without ISI. Radiographic parameters, demographic characteristics, and the Japanese Orthopedic Association (JOA) surgical outcomes score were compared between the groups.
\end{abstract}

Results: Seventeen patients (7.9\%) were diagnosed with SCECS. These patients were younger than those in the non-SCECS group [median (interquartile range), 64 (20) vs. 69 (15) years, respectively, $p=0.016$ ], and the disease duration from onset to surgery was significantly shorter in the SCECS group than in the non-SCECS group [6 (7) vs. 20 (48) months, respectively]. No significant difference was observed between groups with respect to sex, radiologic findings, or surgical outcomes.

Conclusion: The disease showed an earlier onset and more rapid progression in the patients with SCECS than in those without SCECS.

Keywords: Spinal cord edema, Cervical spondylosis, Intramedullary hyperintense lesion, Early-onset, Rapid disease progression

\section{Background}

Most intramedullary lesions in cervical compressive myelopathy are gray matter myelomalacia and present with a snake-eye appearance on T2-weighted MR images (T2WI). Zhou et al. described myelomalacia as a radiographical finding on MRI manifested by an ill-defined area of cord signal change visible on T1- and T2weighted sequences as hypo- and hyperintense areas and commonly associated with focal cord atrophy [1]. Based on autopsy results, Mizuno et al. suggested that the

\footnotetext{
* Correspondence: yoo-tky@umin.ac.jp

'Department of Orthopaedic Surgery, Faculty of Medicine, The University of

Tokyo, 7-3-1 Hongo, Bunkyo-ku, Tokyo 113-0033, Japan

Full list of author information is available at the end of the article
}

snake-eye appearance was a result of cystic necrosis resulting from mechanical compression and venous infarction [2].

Intramedullary hyperintense lesions associated with spinal cord edema on T2WI are rare findings in patients with cervical spondylosis. In a report of six patients with cervical spinal cord edema, Lee et al. speculated that the radiological characterization of spinal cord edema was based on reversible white matter lesions, which were most likely caused by disturbed local venous circulation [3]. Such edematous lesions are liable to be misinterpreted as neoplastic or inflammatory lesions in the spinal canal, and this can delay appropriate treatment. However, intramedullary

(c) The Author(s). 2019 Open Access This article is distributed under the terms of the Creative Commons Attribution 4.0 International License (http://creativecommons.org/licenses/by/4.0/), which permits unrestricted use, distribution, and reproduction in any medium, provided you give appropriate credit to the original author(s) and the source, provide a link to the Creative Commons license, and indicate if changes were made. The Creative Commons Public Domain Dedication waiver (http://creativecommons.org/publicdomain/zero/1.0/) applies to the data made available in this article, unless otherwise stated. 
hyperintense lesions with spinal cord edema are not well characterized in the literature. The purpose of this study was to investigate the clinical characteristics of spinal cord edema due to cervical spondylosis (SCECS).

\section{Methods \\ Subjects}

This retrospective cohort study included 214 patients with cervical spondylotic myelopathy who underwent surgery between April 2007 and March 2017 at our institution. Patients with disc hernia, ossification of the longitudinal ligament, tumors, rheumatoid arthritis, or a history of trauma and spine surgery were excluded. The selection of the surgeon, patients, and operative methods was not randomized.

We divided the patients into two groups, SCECS group and non-SCECS group. Radiographic parameters, demographic characteristics of patients, and surgical outcomes characterized based on the Japanese Orthopedic Association (JOA) score were compared between these two groups.

For further analysis, we divided the patients in the non-SCECS group into three subgroups comprising those negative for ISI on MRI, those positive for ISI only on T2WI, and those positive for ISI on both T1weighted MR images (T1WI) and T2WI. We compared these three groups and the SCECS group with respect to the same factors as in the initial analysis.

\section{Measurements using radiographs and MRI}

Cervical spine radiographs were used to measure the diameter of the spinal canal, C2-7 cervical lordosis (CL), C2-7 range of motion, and segmental range of motion and dynamic instability at the level of greatest stenosis. The definition of dynamic instability was an anterior vertebral slip of $\geq 3.5 \mathrm{~mm}$ or an increase in vertebral angulation in flexion of $\geq 11^{\circ}$, as previously reported [4].

We defined SCECS as follows: (1) intramedullary signal intensity (ISI) of the cervical spinal cord in sagittal T2WI extending to more than one vertebral body height; (2) "fuzzy" ISI, recognized as a faint intramedullary change with a largely indistinct and hazy border; and (3) a larger sagittal diameter of the spinal cord segment with ISI just above or below the cord compression area compared with areas of the cervical spine without ISI.

\section{Statistical analysis}

The Mann-Whitney $U$ test was used for continuous outcomes and the $X^{2}$ test and Fisher's exact test were used for binomial outcomes. The Kruskal-Wallis test with Bonferroni adjustment was used for multiple comparisons. A $p$ value less than 0.05 was considered statistically significant. The analyses were carried out using IBM SPSS Statistics version 19 (IBM Corp., Armonk, New York, United States).

\section{Results}

Of the 214 patients with cervical spondylotic myelopathy who underwent surgery, 17 (7.9\%) were diagnosed with SCECS and assigned to the SCECS group. The nonSCECS group therefore included 197 patients. Of the SCECS group patients, 16 underwent laminoplasty and one underwent anterior cervical discectomy and fusion (ACDF). In the non-SCECS group, 168 patients underwent laminoplasty, 11 underwent pedicle screw fixation, and 18 underwent ACDF. The patients in the SCECS group were younger than those in the non-SCECS group [median (interquartile range), 64 (20) vs. 69 (15) years, respectively, $p=0.016]$ (Table 1 ). The median time from the onset of the disease to surgery was significantly shorter in the SCECS group than in the non-SCECS group [6 (7) vs. 20 (48) months, respectively]. However, no significant between-group differences were observed with respect to sex, preoperative radiologic findings, preoperative JOA score, postoperative JOA score, or JOA recovery rate.

In comparisons involving the SCECS group and the three non-SCECS subgroups (those negative for ISI on MRI, positive for ISI only on T2WI, or positive for ISI on both T1WI and T2WI), the patients in the SCECS group were significantly younger than those in the other groups (Table 2). However, no significant between-group differences were observed with respect to sex, time from disease onset to surgery, preoperative radiologic findings, preoperative JOA score, postoperative JOA, or JOA recovery rate.

We investigated the relevance of preoperative Gdenhanced MRI and postoperative ISI regression to surgical outcomes in the SCECS group. Of the $17 \mathrm{pa}$ tients with SCECS, 11 underwent preoperative Gdenhanced MRI; Gd enhancement was observed in six patients (55\%). Three patients exhibited a pancakelike (i.e., flat and roughly circular) transverse band of Gd enhancement (Fig. 1) [5]. However, the analysis showed that Gd enhancement did not affect the surgical outcomes (Table 3).

Postoperatively, all patients in the SCECS group underwent MRI two weeks after surgery and six of them (35\%) exhibited ISI regression. Of the 11 patients who did not show ISI regression two weeks after surgery, five patients underwent another MRI at final follow-up (1-6 years after surgery), four of whom exhibited ISI regression. In total, 10 (59\%) patients in the SCECS group exhibited ISI regression. There was no significant correlation between the postoperative ISI regression two weeks after surgery and surgical outcomes (Table 4). 
Table 1 Patient characteristics compared between the groups with and without spinal cord edema due to cervical spondylosis (SCECS)

\begin{tabular}{|c|c|c|c|}
\hline & $\begin{array}{l}\text { SCECS } \\
(n=17)\end{array}$ & $\begin{array}{l}\text { Non-SCECS } \\
(n=197)\end{array}$ & $p$ value \\
\hline Age (years) *1 & $64(20)$ & $69(15)$ & ${ }^{*} 0.016$ \\
\hline Male $(\%) * 2$ & $15(88)$ & $135(69)$ & 0.089 \\
\hline $\mathrm{BMI} * 1$ & $25.4(5.3)$ & $23.9(5.1)$ & ${ }^{*} 0.038$ \\
\hline Smoking $(\%) * 2$ & $6(35)$ & $76(39)$ & 1 \\
\hline Time from onset to operation (months) ${ }^{*} 1$ & $6(7)$ & $20(48)$ & ${ }^{*}<0.001$ \\
\hline Postoperative follow-up period (months) ${ }^{*} 1$ & $24(53)$ & $27(41)$ & 0.57 \\
\hline Preoperative $\mathrm{C} 2-7$ cervical lordosis $\left({ }^{\circ}\right){ }^{*} 1$ & $13(17)$ & $13(14)$ & 0.502 \\
\hline Preoperative dynamic instability $(\%) * 3$ & $1(5.8)$ & $21(10.6)$ & 0.455 \\
\hline Preoperative $\mathrm{C} 2-7$ range of motion (degrees) $* 1$ & $35(13)$ & $37(20)$ & 0.399 \\
\hline Preoperative segmental range of motion $\left({ }^{\circ}\right){ }^{*} 1$ & $10(8)$ & $8(6)$ & 0.516 \\
\hline Diameter of the spinal canal $(\mathrm{mm}){ }^{*} 1$ & $14(2)$ & $14(2)$ & 0.913 \\
\hline Preoperative JOA total score ${ }^{*} 1$ & $10.0(4.0)$ & $11.0(3.0)$ & 0.573 \\
\hline Postoperative JOA total score ${ }^{*} 1$ & $13.0(3.5)$ & $12.0(3)$ & 0.887 \\
\hline JOA recovery rate $(\%){ }^{*} 1$ & $37.5(28.5)$ & $28.6(35.7)$ & 0.361 \\
\hline Reoperation $(\%) * 3$ & $0(0)$ & $10(10.3)$ & 0.427 \\
\hline
\end{tabular}

Data are presented as median (interquartile range) or frequencies (\%)

*1 Mann-Whitney U test, *2 $\times 2$ test, *3 Fisher's exact test

\section{Discussion}

\section{The pathophysiology of spinal cord swelling}

In the present study, the patients with SCECS were younger and they showed significantly shorter duration of the disease than those without SCECS. We speculated that the pathology in those with SCECS was different from that in the typical degenerative myelopathy cases. Although the pathophysiology of spinal cord swelling has been poorly understood, involvement of venous hypertension of the spinal cord has been indicated. Lee et al. speculated that impaired venous return due to spinal cord compression causes local venous hypertension, which leads to

Table 2 Comparison of characteristics between the patients with spinal cord edema due to cervical spondylosis (SCECS) group and the three non-SCECS subgroups [those negative for intramedullary signal intensity (ISI) on MRI; those positive for ISI on only T2weighted MR images (T2WI); and those positive for ISI on both T1- and T2-weighted MR images (T1 \& T2WI)]

\begin{tabular}{|c|c|c|c|c|c|}
\hline & $\operatorname{SCECS}(n=17)$ & Negative ISI $(n=82)$ & ISI on T2WI $(n=96)$ & ISI on T1/T2WI $(n=19)$ & $p$ value \\
\hline Age (years) *1 & ${ }^{*} 64(20)$ & *73 (14) & $67(14)$ & $68(17)$ & ${ }^{*} 0.032$ \\
\hline Male $(\%) * 2$ & $15(88)$ & $53(65)$ & $67(70)$ & $14(74)$ & 0.239 \\
\hline BMI $\left(\mathrm{kg} / \mathrm{m}^{2}\right){ }^{*} 1$ & $25.4(5.3)$ & $23.6(4.4)$ & $23.6(5.2)$ & $26.2(5)$ & 0.08 \\
\hline Smoking $(\%) * 2$ & $6(35)$ & $30(37)$ & $36(38)$ & $10(53)$ & 1 \\
\hline Time from onset to operation (months) ${ }^{*} 1$ & $6(7)$ & $21(50)$ & $19(47)$ & $31(45)$ & 0.129 \\
\hline Postoperative follow-up period (months) ${ }^{*} 1$ & $24(53)$ & $24(32)$ & $37(44)$ & $27(45)$ & 0.098 \\
\hline Preoperative $C 2-7$ cervical lordosis $\left({ }^{\circ}\right) * 1$ & $13(17)$ & $14.5(13)$ & $13(13)$ & $5.5(19)$ & 0.11 \\
\hline Preoperative $\mathrm{C} 2-7$ range of motion $\left({ }^{\circ}\right) * 1$ & $35(13)$ & $36.5(21)$ & $36.5(18)$ & $42(21)$ & 0.51 \\
\hline Preoperative segmental range of motion $\left({ }^{\circ}\right){ }^{*} 1$ & $10(8)$ & $7(7)$ & $8.5(6)$ & $7(6)$ & 0.323 \\
\hline Diameter of the spinal canal $(\mathrm{mm}){ }^{*} 1$ & $14(2)$ & $* 14(2)$ & $* 14(1)$ & $14(1)$ & *0.036 \\
\hline Preoperative JOA total score ${ }^{* 1}$ & $10.0(4.0)$ & $10.8(3.0)$ & $11.0(3.0)$ & $11.0(2.3)$ & 0.938 \\
\hline Postoperative JOA total score ${ }^{*} 1$ & $13.0(3.5)$ & $12.0(3.0)$ & $13.0(4.0)$ & $12.0(3.3)$ & 0.754 \\
\hline JOA recovery rate $(\%) * 1$ & $37.5(28.5)$ & $25.0(33.0)$ & $33.3(42.2)$ & $26.8(41.7)$ & 0.499 \\
\hline Reoperation (\%) *2 & $0(0)$ & $7(8.5)$ & $3(3.2)$ & $0(0)$ & 1 \\
\hline
\end{tabular}

Data are presented as median (interquartile range) or frequencies (\%)

*1 Kruskal-Wallis test and Bonferroni adjustment, *2 Fisher's exact test

BMI: body mass index; JOA: Japanese Orthopedic Association surgical outcome score 


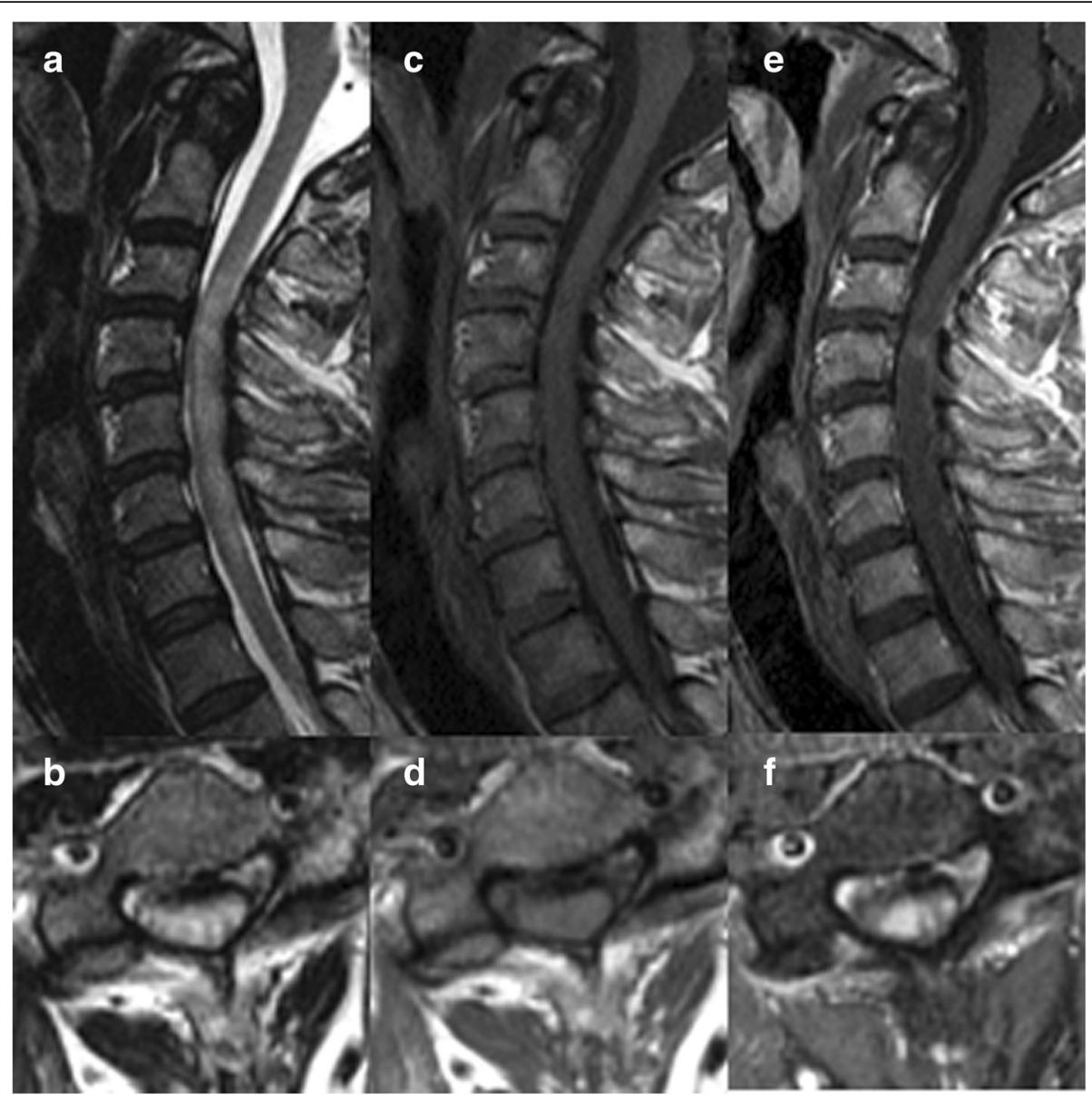

Fig. 1 MRI images of a 53-year-old man with spinal cord edema due to cervical spondylosis revealing T2 high (a, b), T1 iso (c, d) signal intensity, and pancake-like gadolinium enhancement $(\mathbf{e}, \mathbf{f})$

Table 3 Comparison between the patients positive and negative for gadolinium (Gd) enhancement among those with spinal cord edema due to cervical spondylosis

\begin{tabular}{|c|c|c|c|}
\hline & $\begin{array}{l}\text { Gd enhancement }(+) \\
(n=6)\end{array}$ & $\begin{array}{l}\text { Gd enhancement }(-) \\
(n=5)\end{array}$ & $p$ value \\
\hline Age $(y) * 1$ & $63(31)$ & $57(20)$ & 0.855 \\
\hline Male $(\%) * 2$ & $4(66)$ & $5(100)$ & 0.455 \\
\hline Time from onset to operation (months) ${ }^{*} 1$ & $9(10)$ & $5(3)$ & 0.195 \\
\hline Postoperative follow-up period (months) ${ }^{*} 1$ & $18.5(29)$ & $63(41)$ & 0.01 \\
\hline Preoperative $\mathrm{C} 2-7$ range of motion $\left({ }^{\circ}\right) * 1$ & $21.5(20)$ & $32(13)$ & 0.2 \\
\hline Preoperative segmental range of motion $\left(^{\circ}\right)^{*} 1$ & $11.5(6)$ & $4(8)$ & 0.054 \\
\hline Diameter of the spinal canal $(\mathrm{mm}){ }^{*} 1$ & $14.5(1)$ & $14(3)$ & 0.099 \\
\hline Preoperative JOA total score ${ }^{*} 1$ & $10.25(6.3)$ & $12(4.3)$ & 0.199 \\
\hline Postoperative JOA total score ${ }^{*} 1$ & $11.5(4.5)$ & $15(2.5)$ & 0.139 \\
\hline JOA recovery rate $(\%) * 1$ & $25.8(22.7)$ & $50(53.3)$ & 1 \\
\hline
\end{tabular}

Data are presented as median (interquartile range) or frequencies (\%)

*1 Mann-Whitney U test, ${ }^{*} 2 X_{2}$ test

JOA: Japanese Orthopedic Association surgical outcome score 
Table 4 Comparison between the patients with and without intramedullary signal intensity (ISI) regression among those with spinal cord edema due to cervical spondylosis

\begin{tabular}{|c|c|c|c|}
\hline & $\begin{array}{l}\text { ISI regression }(+) \\
(n=6)\end{array}$ & $\begin{array}{l}\text { ISI regression }(-) \\
(n=11)\end{array}$ & $p$ value \\
\hline Age (years) *1 & $67.5(21)$ & $58(23)$ & 0.84 \\
\hline Male $(\%) * 2$ & $6(100)$ & $9(82)$ & 0.52 \\
\hline Time from onset to operation (months) ${ }^{*} 1$ & $7(11)$ & $6(5)$ & 0.477 \\
\hline Postoperative follow-up period (months) ${ }^{*} 1$ & $18.5(44)$ & $24(58)$ & 0.801 \\
\hline Preoperative $\mathrm{C} 2-7$ range of motion $\left({ }^{\circ}\right) * 1$ & $33.5(19)$ & $36(12)$ & 0.546 \\
\hline Preoperative segmental range of motion $\left({ }^{\circ}\right){ }^{*} 1$ & $10.5(6)$ & $9(8)$ & 0.338 \\
\hline Diameter of the spinal canal $(\mathrm{mm}) * 1$ & $14(2)$ & $14(2)$ & 0.372 \\
\hline Preoperative JOA total score ${ }^{*} 1$ & $11(3.9)$ & $9(4)$ & 0.363 \\
\hline Postoperative JOA total score ${ }^{*} 1$ & $14(4.4)$ & $12(2)$ & 0.263 \\
\hline $\mathrm{JOA}$ recovery rate $(\%){ }^{*} 1$ & $46.5(31.6)$ & $30.0(20.0)$ & 0.078 \\
\hline
\end{tabular}

Data are presented as median (interquartile range) or frequencies (\%)

*1 Mann-Whitney $U$ test, ${ }^{*} 2 \times 2$ test

JOA: Japanese Orthopedic Association surgical outcome score

venous ischemia and spinal cord edema at the compression site or adjacent levels [3]. Other authors have suggested that disturbed cerebrospinal fluid (CSF) circulation may play a role in the development of spinal cord edema $[6,7]$. Okada et al. reported a case of venous hypertensive myelopathy associated with cervical spondylosis and hypothesized that cervical canal stenosis and cord compression impaired the spinal venous system, resulting in progressive myelopathy [8]. In addition, mechanical stress by neck motion might be related to the onset of spinal cord swelling, which is still controversial. Sasamori et al. reported that transient but repetitive cord compression was associated with spinal cord swelling and Gd enhancement [9]. Hattou et al. described six young cervical myelopathy patients with non-traumatic cervical chronic joint instability [10].

In addition, six of the 17 patients with SCECS in our study exhibited Gd enhancement (Figs. 1,2). This was a much higher proportion than that found in previous retrospective and prospective studies, which reported Gd enhancement in $7-10 \%$ of patients with cervical spondylotic myelopathy [11-13]. According to the past reports, a breach of the blood-spinal cord barrier (BSCS) of the white matter vessels could be related to the positive intramedullary Gd enhancement, which results in important pathological changes, including cytotoxic edema and vasogenic edema, which were frequently associated with aquaporins (water channel proteins) [3, 14-16]. Aquaporins in the central nervous system (CNS) have mainly been studied with evidence that they play important roles in the pathogenesis of CNS injury, edema, and various diseases such as multiple sclerosis, neuromyelitis optica spectrum disorders, and glioblastoma multiforme [14, 17, 18]. The MRI findings in SCECS resemble the findings in the above pathologies, which indicates the underlying pathophysiological mechanisms are similar.

Based on our findings of earlier onset, more rapid progression, and high proportion of $\mathrm{Gd}$ enhancement, we speculate that the pathogenesis of SCECS was triggered by disturbed venous circulation and the changes in the expression of aquaporins.

\section{Surgical outcomes}

Unlike previous studies $[3,5,19]$, we investigated the differences in surgical outcomes between the SCECS group and non-SCECS subgroups. Various studies have investigated the prognostic significance of ISI on T1WI, T2WI, and Gd enhancement [20-22], but the relevance of these imaging findings to clinical outcome remains controversial.

In the present study, there was no significant difference between the SCECS group and non-SCECS subgroups with respect to surgical outcome. Further, there was no significant correlation between Gd enhancement, postoperative ISI regression, and surgical outcomes. In the study by Lee et al., five of six patients exhibiting ISI regression experienced good improvement of symptoms, although spinal cord edema observed during the follow-up MR imaging persisted for several months after surgery [3]. Flanagan et al. reported that 53 (95\%) of 56 patients with Gd enhancement were stable or improved with Gd enhancement persisting at 12 months in $42(75 \%)$ patients [5]. Lee et al. speculated that the healing process following hyperlucency or a break in the BSCB is longstanding and that the spinal cord recovering its previous function and decompression causes acute reduction of the intravascular resistance, inducing in postoperative aggravation of spinal cord swelling [3]. 


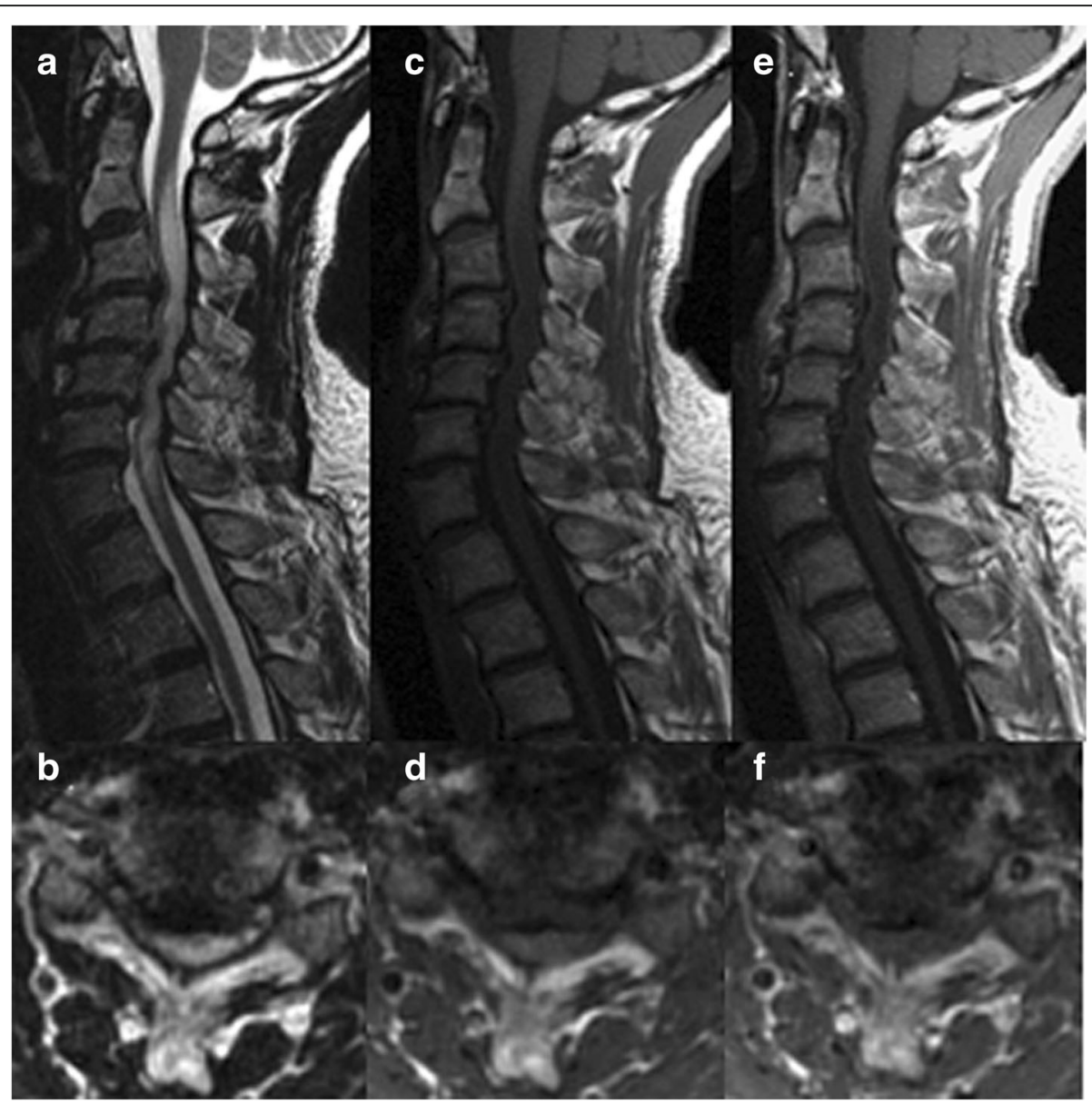

Fig. 2 MRI images of a 67-year-old man with spinal cord edema due to cervical spondylosis revealing T2 high (a, b), T1 iso (c, d) signal intensity, and negative gadolinium enhancement $(\mathbf{e}, \mathbf{f})$

In our study, six of $17(35 \%)$ patients exhibited ISI regression at an early stage after surgery. Further, excluding six patients who exhibited ISI regression at an early stage after surgery, four of 11 (36\%) exhibited ISI regression at the final follow-up. We speculate that SCECS has reversible and unstable features. Although this disease did not affect the surgical outcome, the lack of between-group differences may have been due to the small sample size.

\section{Diagnosis and management}

In the present study, none of the patients with SCECS received an alternative diagnosis postoperatively. Nurboja et al. reported the case of a patient who failed to improve postoperatively and was found to have neurosarcoidosis [19]. Flanagan et al. reported that $40(71 \%)$ of their patients had initially been diagnosed with neoplastic or inflammatory myelopathies with decompressive surgery delayed by a median of 11 months [5]. They recommended that patients who present with T2-high signal changes and contrast enhancement should be closely investigated using brain MRI and CSF, hematological, and biochemical analyses $[5,19]$. We agree with their recommendation; however, most patients with cervical spondylotic myelopathy undergo plain MRI in the clinical setting. Although it was not possible to investigate all the patients with SCECS using Gd-enhanced MRI because of the retrospective nature of this study, we recommend that patients who meet our definition of SCECS should be considered for additional investigations including Gd-enhanced MRI and referred to neurologists (Fig. 3). In our opinion, surgeons should inform patients with SCECS about possible alternative pathologies including tumors, inflammatory disorders before surgery and follow this up postoperatively. In our study, no patient underwent spinal cord biopsy. Flanagan et al. reported the cases of six patients who underwent biopsies which did not reveal any alternative diagnoses. (5) Nurboja et al. proposed that in the first instance, spinal cord decompression should be considered rather than biopsy when no neurological 


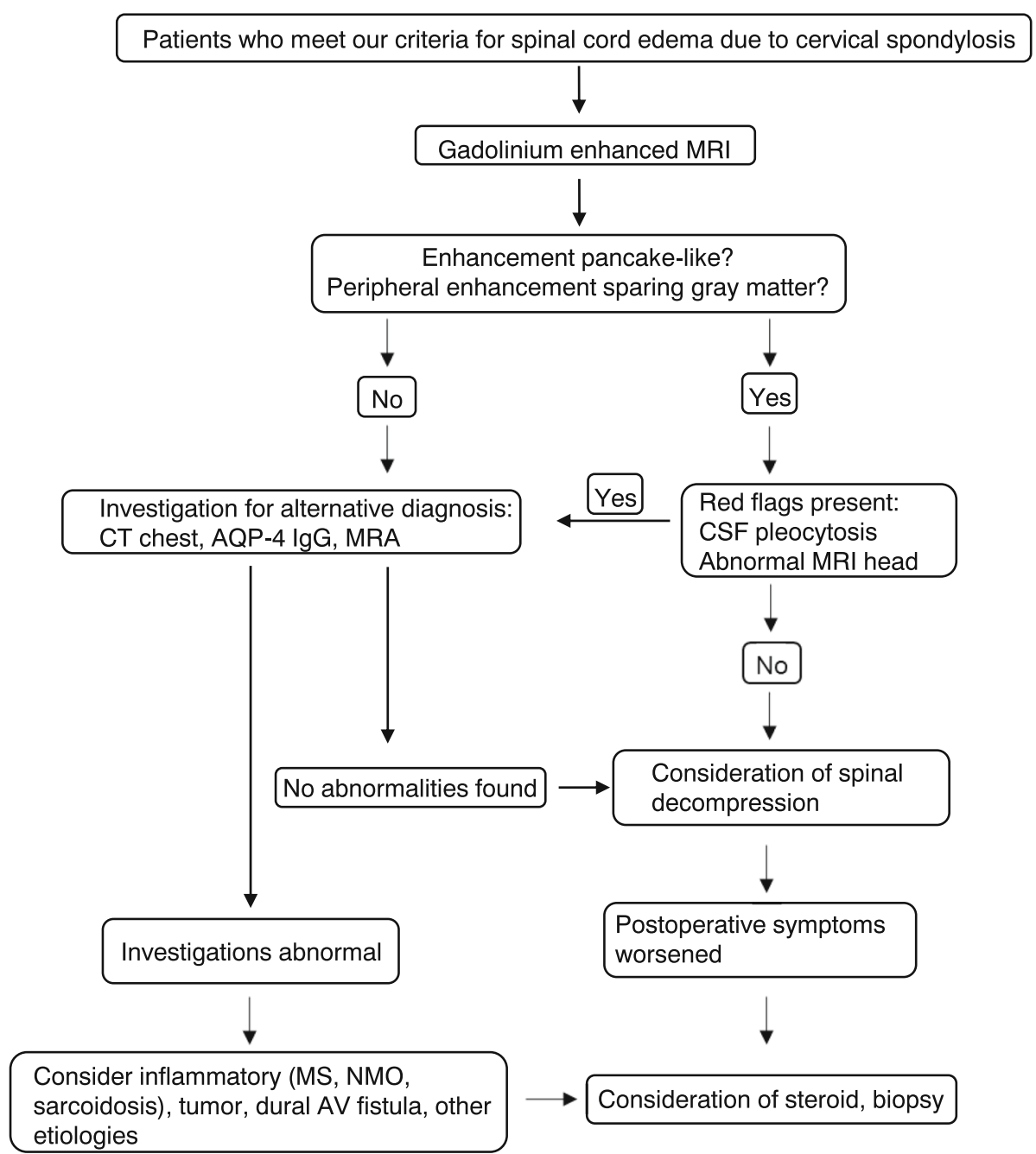

Fig. 3 Algorithm for management of spinal cord edema due to cervical spondylosis, modified from that of Flanagan et al. [5]. AQP4 Aquaporin-4; AV Arteriovenous, CSF Cerebrospinal fluid, CT Computed tomography, IgG Immunoglobulin G, MRA Magnetic resonance angiography; MRI

Magnetic resonance imaging, MS Multiple sclerosis, NMO Neuromyelitis optica

cause is found [19]. Cohen-Gadol et al. reported that specific treatment was determined based on spinal cord biopsy results in only $26 \%$ of patients [23]. They also reported a high (21\%) complication rate for spinal cord biopsy, including neurological deficits. Furthermore, there was no significant difference between the SCECS group and non-SCECS subgroups with respect to surgical outcomes in our study. We therefore recommend that spinal cord biopsy should be considered only when sarcoidosis or intramurally tumors are highly suspected or when postoperative symptoms deteriorate.

\section{Limitations}

The present study had several limitations. First, it was a retrospective study. The follow-up period was relatively short, and the sample size was small. Second, not all patients underwent Gd-enhanced MRI or a thorough investigation to rule out sarcoidosis. Third, there were few data of MRI at the final follow-up. Finally, the patientreported outcomes were not evaluated. Although differences in the JOA scores were not significant, the pain levels or the patient's quality of life may have been affected. Further studies are required to clarify the pathophysiology and more detailed surgical outcomes of the SCECS treatment.

\section{Conclusions}

The incidence of SCECS was $7.9 \%$ in this study. We found that patients with SCECS were significantly younger than those without SCECS and that the time from the onset of the disease to surgery in these patients was significantly shorter; however, surgical outcomes were similar. 


\section{Abbreviations}

ACDF: Anterior cervical discectomy and fusion; BSCB: Blood-spinal cord barrier; CL: Cervical lordosis; CNS: Central nervous system; CSF: Cerebrospinal fluid; ISI: Intramedullary signal intensity; JOA: Japanese Orthopedic Association; SCECS: Spinal cord edema due to cervical spondylosis; T1WI: T1weighted MR images; T2WI: T2-weighted MR images

\section{Acknowledgements}

We have published an E-poster online in forty-fifth annual meeting of the cervical spine research society: http://www.csrs.org/wp-content/uploads/ 2018/02/CSRS_2017_Annual_Meeting_Final_Program_Compressed.pdf.

\section{Authors' contributions}

NT: Protocol/project development, Data analysis, Manuscript writing. TO: Data collection and management, Data analysis. SK: Data analysis, Manuscript editing. YS: Data collection. SO: Data collection. HH: Data collection. SH: Data collection. YT: Data collection. YM: Data collection. HM: Data collection and analysis. ST: Manuscript editing. YO: Protocol/project development, Manuscript editing. All authors read and approved the final manuscript.

\section{Funding}

No funding was received for this study.

\section{Availability of data and materials}

The datasets suporting the conclusions of this article are included within the article. The raw data underlying the conclusions made in this study can be inquired to the first author.

\section{Ethics approval and consent to participate}

All procedures performed in the studies involving human participants were in accordance with the ethical standards of the institutional and/or national research committee and with the 1964 Helsinki Declaration and its later amendments or comparable ethical standards. All the permissions were obtained in order to access the data used in our study.

\section{Consent for publication}

All the images used in this article were completed following obtaining a written informed consent from each patient.

\section{Competing interests}

The authors declares that they have no competing interests.

\section{Author details}

'Department of Orthopaedic Surgery, Faculty of Medicine, The University of Tokyo, 7-3-1 Hongo, Bunkyo-ku, Tokyo 113-0033, Japan. ${ }^{2}$ Department of Radiology, Faculty of Medicine, The University of Tokyo, Tokyo, Japan.

Received: 22 December 2018 Accepted: 10 June 2019

Published online: 14 June 2019

\section{References}

1. Zhou Y, Kim SD, Vo K, Riew KD. Prevalence of cervical myelomalacia in adult patients requiring a cervical magnetic resonance imaging. Spine (Phila Pa 1976). 2015:40(4):E248-52.

2. Mizuno J, Nakagawa H, Inoue T, Hashizume Y. Clinicopathological study of "snake-eye appearance" in compressive myelopathy of the cervical spinal cord. J Neurosurg. 2003;99(2 Suppl):162-8.

3. Lee J, Koyanagi I, Hida K, Seki T, Iwasaki Y, Mitsumori K. Spinal cord edema: unusual magnetic resonance imaging findings in cervical spondylosis. J Neurosurg. 2003;99(1 Suppl):8-13.

4. White AA 3rd, Johnson RM, Panjabi MM, Southwick WO. Biomechanical analysis of clinical stability in the cervical spine. Clin Orthop Relat Res. 1975; 109:85-96.

5. Flanagan EP, Krecke KN, Marsh RW, Giannini C, Keegan BM, Weinshenker BG. Specific pattern of gadolinium enhancement in spondylotic myelopathy. Ann Neurol. 2014;76(1):54-65.

6. Josephson A, Greitz D, Klason T, Olson L, Spenger C. A spinal thecal sac constriction model supports the theory that induced pressure gradients in the cord cause edema and cyst formation. Neurosurgery. 2001;48(3):636-45; discussion 45-6.
7. Klekamp J, Volkel K, Bartels CJ, Samii M. Disturbances of cerebrospinal fluid flow attributable to arachnoid scarring cause interstitial edema of the cat spinal cord. Neurosurgery. 2001;48(1):174-85; discussion 85-6.

8. Okada S, Chang C, Chang G, Yue JJ. Venous hypertensive myelopathy associated with cervical spondylosis. Spine J. 2016;16(11):e751-e4.

9. Sasamori T, Hida K, Yano S, Takeshi A, Iwasaki Y. Spinal cord swelling with abnormal gadolinium-enhancement mimicking intramedullary tumors in cervical spondylosis patients: three case reports and review of the literature. Asian J Neurosurg. 2010;5(2):1-9.

10. Hattou L, Morandi X, Le Reste PJ, Guillin R, Riffaud L, Henaux PL. Dynamic cervical myelopathy in young adults. Eur Spine J. 2014;23(7):1515-22.

11. Takahashi M, Yamashita Y, Sakamoto Y, Kojima R. Chronic cervical cord compression: clinical significance of increased signal intensity on MR images. Radiology. 1989;173(1):219-24.

12. Faiss JH, Schroth G, Grodd W, Koenig E, Will B, Thron A. Central spinal cord lesions in stenosis of the cervical canal. Neuroradiology. 1990;32(2):117-23.

13. Ozawa H, Sato T, Hyodo H, Ishii Y, Morozumi N, Koizumi Y, et al. Clinical significance of intramedullary Gd-DTPA enhancement in cervical myelopathy. Spinal Cord. 2010;48(5):415-22.

14. Li XQ, Fang B, Tan WF, Wang ZL, Sun XJ, Zhang ZL, et al. miR-320a affects spinal cord edema through negatively regulating aquaporin-1 of bloodspinal cord barrier during bimodal stage after ischemia reperfusion injury in rats. BMC Neurosci. 2016;17:10.

15. Huang $X N$, Wang $W Z$, Fu J, Wang HB. The relationship between aquaporin4 expression and blood-brain and spinal cord barrier permeability following experimental autoimmune encephalomyelitis in the rat. Anat Rec (Hoboken). 2011;294(1):46-54.

16. Oklinski MK, Lim JS, Choi HJ, Oklinska P, Skowronski MT, Kwon TH. Immunolocalization of Water Channel proteins AQP1 and AQP4 in rat spinal cord. J Histochem Cytochem. 2014;62(8):598-611.

17. Lennon VA, Wingerchuk DM, Kryzer TJ, Pittock SJ, Lucchinetti CF, Fujihara K, et al. A serum autoantibody marker of neuromyelitis optica: distinction from multiple sclerosis. Lancet. 2004;364(9451):2106-12.

18. Hinson SR, Pittock SJ, Lucchinetti CF, Roemer SF, Fryer JP, Kryzer TJ, et al. Pathogenic potential of IgG binding to water channel extracellular domain in neuromyelitis optica. Neurology. 2007;69(24):2221-31.

19. Nurboja B, Chaudhuri A, David KM, Casey AT, Choi D. Swelling and enhancement of the cervical spinal cord: when is a tumour not a tumour? Br J Neurosurg. 2012;26(4):450-5.

20. Karpova A, Arun R, Cadotte DW, Davis AM, Kulkarni AV, O'Higgins M, et al. Assessment of spinal cord compression by magnetic resonance imaging-can it predict surgical outcomes in degenerative compressive myelopathy? A systematic review. Spine (Phila Pa 1976). 2013;38(16):1409-21.

21. Uchida K, Nakajima H, Takeura N, Yayama T, Guerrero AR, Yoshida A, et al. Prognostic value of changes in spinal cord signal intensity on magnetic resonance imaging in patients with cervical compressive myelopathy. Spine J. 2014;14(8):1601-10.

22. Nouri A, Tetreault L, Zamorano JJ, Dalzell K, Davis AM, Mikulis D, et al. Role of magnetic resonance imaging in predicting surgical outcome in patients with cervical spondylotic myelopathy. Spine (Phila Pa 1976). 2015;40(3):171-8.

23. Cohen-Gadol AA, Zikel OM, Miller GM, Aksamit AJ, Scheithauer BW, Krauss WE. Spinal cord biopsy: a review of 38 cases. Neurosurgery. 2003;52(4):80615 discussion 15-6.

\section{Publisher's Note}

Springer Nature remains neutral with regard to jurisdictional claims in published maps and institutional affiliations.

\section{Ready to submit your research? Choose BMC and benefit from:}

- fast, convenient online submission

- thorough peer review by experienced researchers in your field

- rapid publication on acceptance

- support for research data, including large and complex data types

- gold Open Access which fosters wider collaboration and increased citations

- maximum visibility for your research: over $100 \mathrm{M}$ website views per year

At BMC, research is always in progress.

Learn more biomedcentral.com/submission 